\title{
DIDÁTICA DO PENSAR: uma abordagem teórico-metodológica
}

\author{
Gislene Turatti \\ Roberta Pasqualli2
}

\begin{abstract}
RESUMO
Compromissado com a didática do pensar e baseado nas teorias de Vasili Davydov o projeto Kinesys estimula o estudante a construir conhecimentos por meio de atividades dinâmicas e instrumentalização de conhecimentos científicos. Sendo assim, apresentam-se, aqui, discussões sobre práticas e desafios da docência nas classes de alfabetização no Projeto Kinesys no Colégio Logosófico González Pecotche em Chapecó/SC. Classificada como uma pesquisa descritiva, de abordagem qualitativa, do tipo estudo de caso, fez uso de referenciais teóricos, análise documental e coleta de dados empíricos, por meio de questionários. Como resultados, destaca-se o desafio do coletivo docente de planejar atividades, elaborar e validar material didático específico e da prática de sala de aula visando à valorização de contextos reais de ensino-aprendizagem.
\end{abstract}

Palavras-chave: Prática docente. Metodologia de Ensino. Desafios da docência.

\section{DIDACTICS OF THINKING: a theoretical-methodological approach}

\begin{abstract}
Committed to the didactics of thinking and based on the theories of Vasili Davydov, the Kinesys project encourages students to build knowledge through dynamic activities and instrumentalization of scientific knowledge. Therefore, discussions about teaching practices and challenges in literacy classes are presented here at the Kinesys Project at Colégio Logosófico González Pecotche in Chapecó/SC. Classified as a descriptive research, with a qualitative approach, of the case study type, it made use of theoretical references, document analysis and collection of empirical data, through questionnaires. As a result, the challenge of the teaching collective to plan activities, elaborate and validate specific didactic material and classroom practice is highlighted, aiming at valuing real teaching-learning contexts.
\end{abstract}

Keywords: Teaching practice. Teaching methodology. Teaching challenges.

\footnotetext{
1 Especialista em Teorias e Metodologias da Educação Básica e Profissional, IFSC. Professora do SESC - SC. Orcid iD: https://orcid.org/0000-0002-1543-9337.E-mail: gis@unochapeco.edu.br 2 Doutora em Educação, UFRGS. Docente Permanente do Programa de Pós-Graduação em Educação Profissional e Tecnológica - ProfEPT IFSC. Orcid iD: https://orcid.org/0000-00021543-9337. E-mail: roberta.pasqualli@ifsc.edu.br
} 


\title{
DIDÁCTICA DEL PENSAMIENTO: un enfoque teórico-metodológico
}

\section{RESUMEN}

Comprometido con la didáctica del pensamiento y basado en las teorías de Vasili Davydov, el proyecto Kinesys anima al alumno a construir conocimiento a través de actividades dinámicas e instrumentalización del conocimiento científico. Por lo tanto, las discusiones sobre las prácticas docentes y los desafíos en las clases de alfabetización se presentan aquí en el Proyecto Kinesys en el Colégio Logosófico González Pecotche en Chapecó/SC. Clasificada como una investigación descriptiva, con un enfoque cualitativo, del tipo estudio de caso, hizo uso de referencias teóricas, análisis documental y recolección de datos empíricos, a través de cuestionarios. Como resultado, se destaca el desafío del colectivo docente de planificar actividades, elaborar y validar material didáctico específico y la práctica en el aula, con el objetivo de valorar contextos reales de enseñanza-aprendizaje.

Palabras clave: Práctica docente. Metodología de la enseñanza. Desafíos docentes.

\section{INTRODUÇÃO}

\begin{abstract}
Mas, se todo o mal está nisso!... Nas palavras. Todos trazemos dentro de nós um mundo de coisas: cada qual tem o seu mundo de coisas! E como podemos entender-se nos, senhor, se nas palavras que digo, ponho o sentido do valor das coisas como são dentro de mim, enquanto quem as ouve lhes dá, inevitavelmente, o sentido e o valor que elas têm para ele, no mundo que traz consigo? Pensamos entender-nos...e jamais nos entendemos (PIRANDELLO, 2004, p. 377).
\end{abstract}

Ao iniciar as discussões com Pirandello (2004) em "Seis personagens à busca de um autor" depare-se com a reflexão de como as palavras se deixam vestir pelas experiências individuais. $\bigcirc$ diálogo que se estabelece é configurado a partir de sentidos e compreensões compartilhadas e constituídas por sujeitos e, por isso, a importância do tema posto em tela: a implementação do projeto Kinesys no Colégio Logosófico Gonzaléz Pecotche em Chapecó, Santa Catarina (SC).

Nesta direção, o objetivo desta pesquisa é analisar as práticas e os desafios da docência nas classes de alfabetização no Projeto Kinesys no Colégio Logosófico González Pecotche em Chapecó - SC.

A partir de 2019, por meio do Projeto Kinesys, gestores, professores e estudantes vivenciaram os desafios da inclusão de práticas que 
oportunizaram a construção de narrativas intercambiadas nos espaços físicos internos e externos da instituição e foram nestes espaços que se enunciaram dúvidas, saberes e interações entre os sujeitos da escola.

No decorrer da implementação do projeto Kinesys, foram surgindo inquietações que, permeadas pelo diálogo entre os professores que participaram desse projeto, apontam a relevância e o teor inovador da temática da pesquisa ora apresentada.

Entre estas inquietações, destacam-se as que deram corpo para esta pesquisa que, do ponto de vista da sistematização deste artigo apresentamse como: (a) o que é o projeto Kinesys e como é a sua organização no aspecto de ensino-aprendizagem? e, (b) quais as práticas docentes e os desafios inerentes à materialização desta prática?

Com esta perspectiva demarcada, o estudo aqui apresentado se constituiu como uma leitura das práticas dos professores que atuam nas classes de alfabetização no projeto Kinesys no Colégio Logosófico Gonzaléz Pecotche em Chapecó - SC e dos desafios apresentados à docência dentro desta perspectiva teórico-prática de atuação.

Cabe destacar, já no início deste texto, que a perspectiva teórica do projeto Kinesys se ampara na teoria da atividade, postulada por Davydov (1988).

A pesquisa está organizada em 3 seções: inicia apontando o percurso metodológico trilhado na investigação, seguido de uma revisão acerca da base teórica que subsidiou a construção do projeto Kinesys. O terceiro momento apresenta os resultados e discussões oriundas do intercâmbio entre a pesquisa empírica e dos referenciais teóricos privilegiados.

Por fim, são discorridas as considerações finais oriundas deste estudo e apresentadas as referências utilizadas.

\section{PERCURSO METODOLÓGICO}

Considerando seu propósito, este estudo se caracterizou como pesquisa exploratória e descritiva que buscou apresentar a temática, com vistas a torná-la mais compreensível, assim como uma descrição mais 
detalhada de suas características (GIL, 2008). Foi desenvolvido seguindo a abordagem qualitativa e dialética e seguiu a orientação de Minayo (2002), ou seja, a pesquisa qualitativa trabalha com o universo de significados, motivos, aspirações, crenças, valores e atitudes, o que corresponde a um espaço mais profundo das relações, dos processos e dos fenômenos que não podem ser reduzidos à operacionalização de variáveis.

A pesquisa foi realizada a partir de material constituído de livros, artigos de periódicos e material disponibilizado na internet com incidência em obras de autores como Vygostky (2004) e Davydov (1988), entre outros.

Define-se esta pesquisa como um estudo de caso que é visto como um método de pesquisa que utiliza, geralmente, dados qualitativos, coletados a partir de eventos reais, com o objetivo de explicar, explorar ou descrever fenômenos atuais inseridos em seu próprio contexto (YIN, 2001).

Foram convidados para ser sujeitos da pesquisa os professores que atuavam no Colégio Logosófico Gonzaléz Pecotche em Chapecó - SC no ano de 2019, sendo eles: os professores regentes do $1^{\circ}$ e $2^{\circ}$ ano do ensino fundamental e os professores de Música, Artes, Espanhol, Educação Física, e Educação Ambiental, consideradas áreas especializadas. Dos 9 professores convidados, 5 professores participaram como respondentes da pesquisa. A coleta de dados foi realizada por meio de questionário contendo 9 perguntas abertas, das quais apenas 7 foram consideradas para fins de análise em virtude das respostas se entrecruzarem. Foram considerados os aspectos éticos da pesquisa com seres humanos com a legislação vigente.

\section{O PROJETO KINESYS: diferentes olhares acerca da concepção de ensino- aprendizagem}

O objetivo desta seção é apresentar a base teórica que subsidiou a construção do projeto Kinesys, exemplificando como a teoria da atividade contribuiu para a compreensão das relações de ensino-aprendizagem vinculadas aos processos sociais e culturais. Para iniciarmos a discussão destaca-se que Davydov (1988, p.1), desenvolveu a teoria da atividade que, segundo o autor, é um "conceito filosófico-pedagógico de atividade" que 
[...] significa transformação criativa pelas pessoas da realidade atual. A forma original desta transformação é o trabalho. Todos os tipos de atividade material e espiritual do homem são derivados do trabalho e carregam em si um traço principal - a transformação criativa da realidade e, ao final, também do próprio homem (DAVYDOV, 1988, p. 1).

A partir disto, considera-se que a atividade constitui-se numa prática cultural e social de forma intencional de produção e internalização do conhecimento, materializada por meio da promoção do desenvolvimento cognitivo, moral e afetivo dos estudantes.

Nesta direção, surge como indagação, qual o papel do professor frente a esta metodologia. Segundo a perspectiva de Davydov (1988), é preciso que os professores estimulem a capacidade de raciocínio e reflexão para que os estudantes sejam capazes de pensar e resolver problemas diante das situações da vida cotidiana. Assim, frente a parte pedagógica, na elaboração das atividades, o professor deve buscar atingir a essência do objeto para fazer sentido aos estudantes.

De acordo com Davydov (1988), a escola tem o papel fundamental de desenvolver nos estudantes as competências e habilidades exigidas pela sociedade, considerando as redes de comunicação e a necessidade de se adaptar no mundo atual: é preciso educar sujeitos ancorados moralmente e flexíveis em suas personalidades. Davydov (1988) parte da teoria de Vygotsky (2003) ${ }^{3}$ em que estudou o mundo psíquico na sua construção histórica e social da humanidade.

Uma das contribuições relevantes de Vygotsky (2004) sobre a aprendizagem significativa parte das funções psicológicas superiores, sendo a capacidade de planejamento, a memorização, o pensamento abstrato e ações controladas que constituímos a partir da cultura e do meio. Para Vygotsky (2004), os estudos sobre o psiquismo humano não é algo pronto, uma vez que seus estudos buscaram compreender a forma como o sujeito se desenvolve e aprende, sendo 0 indivíduo integrante de sua própria

\footnotetext{
3 Primeira edição de 1978.
} 
evolução no processo histórico que desenvolve suas capacidades por meio da cultura.

Sendo assim, os sujeitos precisam da mediação, a qual tem o papel fundamental na intervenção da sua realidade. Vygotsky (2004) estudou dois tipos de mediadores chamados de instrumentos e signos. Para Vygotsky (2004), o instrumento serve para suprir as necessidades humanas, para ter uma condição de vida melhor.

Por outro lado, o signo desempenha a função da mediação, visto o significado da representação, por exemplo: o banheiro possui duas placas de identificação - um boneco de feminino e outro de masculino - e é por meio desses signos (bonecos) que nós sabemos qual é o significado. Por meio do signo e da apropriação do conhecimento o sujeito consegue ter o pensamento abstrato sem precisar do concreto (VYGOTSKY, 2004).

Nesse sentido, para se tornar um sujeito, é necessário a interação humana. O sujeito, por meio do conhecimento, não tem a impressão imediata, mas a partir da cultura ele constituirá seu próprio comportamento, adquirindo conceitos, transformando suas ideias.

Em razão da contextualização dos impactos nos meios de comunicação e as diferentes formas de mediação e a configuração de maneiras de pensar, a didática precisa se adequar ao modo como os sujeitos aprendem, discutindo e reelaborando o papel do professor nessa mediação visando a didática do pensar. Assim, para realizar um trabalho significativo o professor precisa observar, investigar, sistematizar e comunicar experiências e situações vivenciadas, ou seja, o que lhe chame a atenção. O domínio dos saberes específicos e didático-pedagógicos são exigências primordiais para a atuação do professor, mas além disso ele deve exercer a capacidade de suscitar no estudante o entusiasmo pela aprendizagem do pensar. Vygotsky (2004), contribuindo com colocações sobre o papel profissional do professor destaca:

[...] um profissional cientificamente instruído é um professor de verdade antes de ser um matemático [...]. A complexidade crescente das tarefas que se coloca perante o professor, 0 
número de procedimentos exigidos tornou-se tão infinitamente diversificado e tão complicado que, se o professor quiser ser um pedagogo cientificamente instruído, deve ter um embasamento cultural muito vasto (VYGOTSKY, 2004, p. 455).

De acordo com o autor, por meio do objeto ou do conhecimento científico do ensinar, o professor estará ligando a escola com a vida dos estudantes. Para ele, o resultado das aprendizagens e concepções construídas pelos estudantes está associado à forma como o professor realiza sua atividade didático-pedagógica.

Desta maneira, as atividades didático-pedagógicas precisam ser socialmente úteis para a vida do estudante, permitindo a possibilidade de que ele se debruce diante dos fundamentos da ciência com independência cognitiva.

Ancorado nos pressupostos de Vygotsky (2003), Davydov (1988), enfatizou que a criança aprende principalmente com seu meio, com a mediação cultural, viabilizando os significados em seu dia a dia pois, por meio da cultura, desenvolve o senso crítico das pessoas e assim, uns aprendem com os outros. Segundo Libâneo (2004) que explica sobre a teoria de atividade de Davydov (1988),

Com efeito, as crianças e jovens vão à escola para aprender cultura e internalizar os meios cognitivos de compreender e transformar o mundo. Para isso, é necessário pensar - estimular a capacidade de raciocínio e julgamento, melhorar a capacidade reflexiva e desenvolver as competências do pensar. A didática tem o compromisso com a busca da qualidade cognitiva das aprendizagens, esta, por sua vez, associada à aprendizagem do pensar. Cabe-lhe investigar como ajudar os alunos a se constituírem como sujeitos pensantes e críticos, capazes de pensar e lidar com conceitos, argumentar, resolver problemas, diante de dilemas e problemas da vida prática (LIBÂNEO, 2004, p. 5).

Davydov (1988) não desconsidera o ensino da escola tradicional, mas evidencia pontos que precisam ser ajustados, pois a sociedade carece de mudanças e inovações que podem ser promovidas por meio do ensino. Davydov (1988) incorporou premissas de Vygotsky (2003), concretizando sua 
teoria do ensino desenvolvimental em que, segundo o autor, o papel da escola é ensinar os estudantes a orientar-se e a pensar mediante aos saberes que impulsionam seus conhecimentos.

Davydov (1988) apresenta propostas de ensino que viabilizam a melhoria do processo de ensino-aprendizagem. A primeira proposta é a integração entre os conteúdos científicos e a cognição do estudante. Para esta proposta, os professores precisam desenvolver a capacidade e as habilidades dos estudantes de acordo com o conhecimento científico, sendo possível a aplicabilidade.

A segunda proposta desenvolvida pelo autor é a necessidade de que haja correspondência entre a análise de conteúdo e as motivações dos estudantes nos processos de ensino-aprendizagem. Assim, o papel do professor é debruçar-se frente ao conhecimento e buscar a motivação para que os estudantes aprendam e se apropriem do conhecimento.

A última proposta, não menos importante, é a fundamentação teórica dos professores em relação aos saberes e a proposta didático-metodológica de ensinar. Esta proposta refere-se ao aspecto relacionado à formação inicial e continuada dos professores, na qual o professor precisa ter domínio do conteúdo, das instrumentalizações e das habilidades e capacidades específicas das técnicas de ensinar.

Outro ponto importante apontado nas teorias de Vygotsky (2003), Davydov (1988) e Libâneo (2004) auxilia na compreensão de que para assumir um papel significativo na educação é relevante a formação continuada dos professores, assim Libâneo (2004) ressalta alguns requisitos a serem considerados no programa de professores,

[...] a análise do conteúdo da formação dos alunos, implicando os conteúdos das matérias formativas e os procedimentos pelos quais se trabalha essas matérias; 2) as motivações dos alunos, considerando-se a estrutura da atividade nesse nível de formação, em que se combina a atividade profissional e a atividade de aprendizagem (LIBÂNEO, 2004. p. 136). 
Em outras palavras, é fundamental que a formação de professores tenha foco no desenvolvimento do pensamento crítico e na sua produção de forma consciente, na qual os materiais e estudos partam de aprendizagens para os estudantes de forma ativa.

Nesse sentido, o projeto Kinesys, com sua equipe de profissionais formada por mestres e doutores de diversas áreas do conhecimento busca orientar os professores do Colégio Logosófico de Chapecó - SC nos processos de ensinar e aprender num movimento espiral, que tem como base as experiências, vivências, ações e práticas, evoluindo para atividades cognitivas e sistematizadas em registros sustentados em análises e sínteses que permitam a elaboração de conceitos.

Na sequência, apresenta-se as análises e as discussões a partir dos dados obtidos neste estudo.

\section{RESULTADOS E DISCUSSÕES}

As análises e discussões apresentadas nesta seção foram produzidas a partir da aproximação teórica entre as proposições dos autores estudados, dos dados empíricos obtidos durante a análise dos resultados do instrumento de pesquisa e dos achados de estudos semelhantes. Estas discussões e análises visam contribuir para as reflexões sobre a problemática desta pesquisa.

Para a análise dos dados, as respostas foram transcritas e os respondentes foram identificados pela letra $P$ de professor e número em ordem crescente de questionários analisados a partir de 1 . Foi realizado o agrupamento temático das falas correspondentes a cada indagação proposta no instrumento de coleta de dados desta pesquisa.

O tempo de docência dos professores que participaram do projeto Kinesys no Colégio Logosófico em Chapecó - SC foi objeto de investigação, uma vez que se entendeu, a priori, que corpos docentes caracterizados como iniciantes poderiam apresentar características de docência diferenciadas dos professores considerados mais experientes. Este pressuposto não se apresentou verdadeiro, já que se observou que o tempo 
de docência dos professores variou muito entre os respondentes da pesquisa e as respostas às demais questões não apresentaram núcleos significativos de divergências. Destaca-se que o tempo de docência variou de 1 a 24 anos.

$\mathrm{Na}$ expectativa de investigar processos interdisciplinares na docência dos professores que participaram do projeto Kinesys, buscou-se a perspectiva da interdisciplinaridade que deve integrar-se em outras áreas específicas com o objetivo da interação entre o professor, estudante e com a realidade vivida. Nesta direção,

A interdisciplinaridade não dilui as disciplinas, ao contrário, mantém sua individualidade. Mas integra as disciplinas a partir da compreensão das múltiplas causas ou fatores que intervêm sobre a realidade e trabalha todas as linguagens necessárias para a constituição de conhecimentos, comunicação e negociação de significados e registro sistemático dos resultados BRASIL (1999, p. 89).

Assim, o segundo questionamento que os respondentes da pesquisa responderam foi se "consideravam o conceito de interdisciplinaridade para sua atuação docente no Kinesys'. Observou-se, como respostas, às seguintes manifestações:

QUADRO 1 - Sobre interdisciplinaridade no projeto Kinesys

\begin{tabular}{|l|l|}
\hline P1 & $\begin{array}{l}\text { O material por si só já propõe práticas que permeiam as diferentes áreas e } \\
\text { considerando a interdisciplinaridade [..] como professora regente da turma, me } \\
\text { reconheço como a professora que muitas vezes é a ponte entre todas as áreas } \\
\text { especializadas, no diálogo, sugerindo possibilidades [...]. }\end{array}$ \\
\hline P2 & $\begin{array}{l}\text { Como professora de [...], percebo que o conteúdo que exploro com a [...] está } \\
\text { conectado com todos os outros conteúdos trabalhados o que, de certa forma, } \\
\text { facilita a aprendizagem [...]. }\end{array}$ \\
\hline P4 & $\begin{array}{l}\text { Participo de reuniões semanais onde analisamos todas as aulas e atividades de } \\
\text { todos os componentes curriculares. Ao ministrar minha aula faço referências ao } \\
\text { que foi aprendido, buscando inserir em meu planejamento o que está sendo } \\
\text { visto em outros componentes curriculares. }\end{array}$ \\
\hline P5 & $\begin{array}{l}\text { Os professores da turma se encontram toda a semana para ler a aula e pensar } \\
\text { em algumas estratégias para levar o conteúdo para as crianças. [...] No } \\
\text { próprio material didático as atividades são interdisciplinares, facilitando assim a } \\
\text { interdisciplinaridade. }\end{array}$ \\
\hline
\end{tabular}

Fonte: As autoras. 
De acordo com as respostas apresentadas no Quadro 1, considera-se que o pensar interdisciplinar correlaciona outras formas de conhecimento e não há eliminação da identidade dos componentes curriculares, mas sim, tornam-se comunicativos entre si, constituindo processos culturais e históricos.

Compreende-se, a partir das manifestações dos professores, que a interdisciplinaridade é entendida como uma forma potencial de trabalhar em sala de aula e entender as partes que se aproximam entre as diferentes áreas, potencializando possibilidades e descobertas de sabedorias ultrapassando o pensar fragmentado.

Concorda-se, então, que existe a necessidade da aplicação da interdisciplinaridade na produção de saberes já que esta, na perspectiva do projeto Kinesys, busca superar a visão fragmentada na produção do conhecimento destacando que o próprio homem é um sujeito social sendo um objeto de conhecimento social, como destacam os estudos de Frigotto (1995). Nessa premissa, considera-se que a interdisciplinaridade descrita pelos respondentes da pesquisa, utiliza os conhecimentos de vários componentes curriculares, capazes de resolver determinado fenômeno a partir de diversos pontos de vista. Nesta direção, concorda-se com Frison (2000),

Como na escola o aprendizado é um resultado desejável, é o próprio objetivo do processo escolar, a intervenção é um processo pedagógico privilegiado. O professor tem o papel explícito de intervir e provocar nos alunos avanços que não ocorreriam espontaneamente (FRISON, 2000 p. 129).

Compreende-se que, na atualidade, com os avanços tecnológicos em um mundo globalizado o professor não é apenas o provedor do saber, mas atua como mediador do conhecimento. O objetivo do professor é, entre tantos outros, em suas metodologias, questionar os estudantes lançando desafios que sejam possíveis de serem respondidos e instigadores de enfrentamentos.

Caminhando para o próximo questionamento desta pesquisa, destaca-se que a elaboração do material didático no projeto Kinesys, em consonância com a Base Nacional Comum Curricular (BNCC), contempla a 
integração das áreas e objetos de conhecimento, considerando fortemente aspectos interdisciplinares desde a sua essência. Como principais objetivos na elaboração e execução do material pedagógico do projeto Kinesys, destaca-se: (a) nas atividades, é possível o professor identificar os pontos de referência para rever e organizar suas ações; (b) não tem uma sequência de número de páginas, o professor tem a liberdade de escolher o momento certo de abordar determinado conhecimento; (c) trabalhar a interdisciplinaridade dos conteúdos e, (d) desenvolvimento da criatividade por meio da didática do pensar.

Compreende-se, assim, que o material parte do desenvolvimento cognitivo, emocional, afetivo e físico, de maneira que consistem em transformações e realizações de interação entre os estudantes e professores com o mundo já que,

[...] para desenvolver um trabalho educacional-pedagógico na perspectiva indicada nesta proposta é preciso entender que a educação é uma prática social que precisa da contribuição das outras áreas do conhecimento fundamentado o seu trabalho, de forma interdisciplinar (SANTA CATARINA, 1998, p. 22).

Na sequência da pesquisa, buscou-se investigar 'como a didática do pensar é aplicada no processo de ensino-aprendizagem no projeto Kinesys' e, para isto, foi solicitado aos respondentes que considerassem, para suas respostas, 'desde o planejamento, passando pela sua parcela de participação na elaboração do material didático, a materialização da prática na sala e a avaliação da aprendizagem'.

Um aspecto importante para que o professor realize um trabalho efetivo é a importância do planejamento. Vasconcellos (1995), em seus estudos, explica que planejar é antever uma ação que vai se realizar, o planejamento pode ser utilizado como um instrumento de trabalho pedagógico, por meio dele é possível a transformação sobre a realidade contendo registros e informações importantes. 
Vasconcellos (1995, p. 27) afirma que "se planejar significa antever uma intervenção na realidade visando sua mudança, a possibilidade do planejamento está intrinsecamente ligada à possibilidade desta transformação vir a ocorrer". Sendo assim, a partir do ponto de vista de Vasconcellos (1995), para se planejar é preciso levar em conta as necessidades da criança, tempo, espaço, material, didática e o currículo adequado.

A função é favorecer e criar estratégias auxiliando no processo de aprendizagem dos estudantes, investindo nas interações dos sujeitos, sendo o professor mediador do processo surgiu como respostas para esta pesquisa.

QUADRO 2 - Aplicação da Didática do pensar

\begin{tabular}{|l|l|}
\hline P1 & $\begin{array}{l}\text { [..] sinto que é um material dinâmico, que abre possibilidade para várias } \\
\text { práticas, sendo assim sem perder o objetivo que é o guia, temos também } \\
\text { liberdade de optar por como vamos aplicar estas práticas, e temos que nos } \\
\text { movimentar para oferecer um momento como conhecimento. [...] Assim como } \\
\text { o aluno não é somente um reprodutor dos conhecimentos porque os constrói } \\
\text { através de experiências de aprendizagem, o professor também entra neste } \\
\text { movimento de estudo em busca de conhecimentos para estruturar suas aulas } \\
\text { [...]. }\end{array}$ \\
\hline P2 & $\begin{array}{l}\text { Um dos objetivos do projeto é fazer o aluno pensar [...]. Esse método já deve } \\
\text { ser pensado no momento de planejar a aula até o momento de executar a } \\
\text { atividade, considerando que podem aparecer diferentes caminhos para } \\
\text { chegarem ao mesmo resultado. [...] eles podem buscar respostas no dia a dia } \\
\text { deles, em pesquisas e conteúdos recentemente estudados. A resposta, muitas } \\
\text { vezes, não é a mesma para todos os alunos. Isso amplia muito o pensar [...]. }\end{array}$ \\
\hline P4 & $\begin{array}{l}\text { [...] busco organizar para que a criança não tenha nada "pronto", [...] me } \\
\text { organizo para que eu sempre tenha tempo para ouvir à todos que queiram } \\
\text { participar. [...] peço para que explorem e busquem os materiais que mais Ihe } \\
\text { agradem e, raramente dou exemplos [...] que não pensem que o meu modo } \\
\text { de fazer deva ser copiado. }\end{array}$ \\
\hline P5 & $\begin{array}{l}\text { O material didático promove a busca do conhecimento pelo professor antes } \\
\text { para ensinar depois. [...]. A didática do pensar inicia antes no professor. Depois, } \\
\text { na hora de estar com os alunos, o próprio material e a atitude docente } \\
\text { promove o pensar na criança. As perguntas são uma constante e as atividades } \\
\text { vão sugerindo que a criança vá criando hipóteses até que o professor elucide } \\
\text { suas dúvidas e vá construindo o conhecimento junto com os alunos. }\end{array}$ \\
\hline
\end{tabular}

Fonte: As autoras. 
Observa-se que a essência da atividade é perceber a concretude dos materiais pedagógicos elaborados pelos professores captando os processos de ensinar e aprender, assim buscando a totalidade da compreensão dos saberes na formação do sujeito integral.

De acordo com Davydov (1988) o desenvolvimento do ser humano deve ser considerado em todo o processo de educação pautado em aspectos, ideológicos, políticos e laborais, moral e fisicamente na sua totalidade dialética. Ainda, segundo o mesmo autor, a essência do exercício do sujeito pode ser descoberta no percurso de análise dos conteúdos e os conceitos que estão relacionados com o trabalho de organização da troca da relação entre professor e estudante.

Para Davydov (1988) ao analisar a atividade real do sujeito é preciso definir a necessidade e os motivos da atividade em questão, por isso os conteúdos partem da realidade dos estudantes e os procedimentos da ação dirigida pelo professor para que o educando resolva determinada atividade, constituindo o objetivo real de exercício.

Percebe-se, de acordo com as respostas obtidas, que as atividades pedagógicas são a construção da consciência humana e, nesta direção, concorda-se com Davydov (1988) que a consciência é uma forma de desenvolvimento superior em que o sujeito é capaz de desenvolver suas funções, a realidade objetiva construindo na imagem sua satisfação na aprendizagem.

Nota-se que os professores lançam mão de materiais concretos para os estudantes manipularem, observar, construir, desenhar para vincular com o real, mas, além disto, levar seus estudantes a pensar em diferentes estratégias para possibilidades diversificadas de resolver as atividades pedagógicas.

Concebe-se nas respostas dos professores a construção do diálogo e, por isto, concordamos com Nunes e Carvalho (2007, p. 23) quando estes afirmam que 'dar voz' não se trata apenas de deixar as crianças falar ou expressarem seus pontos de vista, mas, sim, de explorar a contribuição única que as suas perspectivas providenciam. Percebemos o quanto é significativo 
- diálogo, para auxiliar na aproximação e para que seja possível a problematização de diversos conteúdos, conhecimentos, dúvidas e estabelecendo vinculações permanentes entre sujeitos.

Observa-se, a partir dos relatos dos professores, que estes constroem um olhar sensível e atento em relação aos estudantes, atentos e ouvintes em suas metodologias e, buscou-se em Silva, Barbosa e Kramer (2005) a importância de reeducar o olhar utilizando um termo chamado de 'auscultar', uma vez que ouvir é simplesmente receber as informações, já auscultar é compreender a comunicação do estudante, interpretando e analisando o diálogo.

[...] Ver e ouvir são cruciais para que se possa compreender gestos, discursos e ações. Este aprender de novo a ver e ouvir (a estar lá afastado; a participar e anotar; a interagir enquanto observa a interação) se alicerça na sensibilidade e na teoria e é produzida na investigação, mas é também um exercício que se enraíza na trajetória vivida (SILVA; BARBOSA; KRAMER, 2005, p. 48).

Sendo assim, considera-se que o material didático no projeto Kinesys é dinâmico e possibilita a criação de inúmeras estratégias de ensino e práticas metodológicas.

Na sequência da pesquisa questionou-se os professores sobre 'como o projeto Kinesys contribui para a construção do ensinar a pensar, um dos pressupostos da Pedagogia Logosófica', compreendendo que o papel do professor interessado no desenvolvimento integral dos estudantes perpassa a ampliação da capacidade do pensar, incentivando a criatividade e o intelectual.

Nesse complexo processo de interação e convivência com diferentes possibilidades e maneiras de pensar o sujeito desenvolve suas capacidades de criatividade, autonomia, diálogo e apropriação de diferentes saberes. 
QUADRO 3 - Contribuição para a construção do ensinar a pensar

\begin{tabular}{|l|l|}
\hline P1 & $\begin{array}{l}\text { O aluno está sempre sendo instigado a pensar, a entender como funciona o } \\
\text { que propomos, assim como a pedagogia logosófica que oferece ferramentas } \\
\text { que movimentem o ser humano a se tornar cada vez mais consciente de si e } \\
\text { do mundo que vive. O pensar sobre o mundo deve passar pelo pensar sobre si, } \\
\text { sendo que somos seres atuantes nestes conhecimentos que são sobre o mundo } \\
\text { que nos rodeiam. }\end{array}$ \\
\hline P2 & $\begin{array}{l}\text { Penso que desde o momento que se parte da prática para a teoria. Primeiro a } \\
\text { criança vive, experimenta, [...], se encontra dentro do processo [...] antes de } \\
\text { teorizar, preencher, calcular, escrever... Isso a torna mais autônoma e segura. }\end{array}$ \\
\hline P4 & $\begin{array}{l}\text { Os alunos também aprendem a desenvolver o senso ou a leitura crítica, } \\
\text { aprendendo a questionar e ir em busca de informações. Não esperam tudo } \\
\text { "pronto" e não aceitam uma única resposta como verdadeira. [...]. }\end{array}$ \\
\hline P5 & $\begin{array}{l}\text { Primeiro os conhecimentos são aprofundados, não são levados de forma } \\
\text { superficial, [...] e, não é porque são crianças pequenas que precisamos levar } \\
\text { conhecimentos pequenos, simplistas. [...] a criança vai se aproximando antes } \\
\text { pelo sentir.[...] Uma atividade tem relação com a outra, uma aula tem relação } \\
\text { com a outra e assim a criança vai vivenciando diversas atividades que vão } \\
\text { promovendo aprendizagens significativas. }\end{array}$ \\
\hline
\end{tabular}

Fonte: As autoras.

Percebeu-se que os professores concordam que o conhecimento não é algo pronto, mas fruto de uma interação entre o estudante com o objeto de conhecimento. Entende-se que é importante refletir que a participação do professor na busca de diferentes possibilidades de ensino é uma ação que contribui na autonomia.

Assim o desenvolvimento cognitivo e as capacidades de pensar, Ultrapassam a concepção de aprendizagem por meio de 'colagem' e 'repetição' ou, apenas, pela 'memorização dos conteúdos'. Surge um ensino inovador que mobiliza os sujeitos para a descoberta, desenvolvendo habilidades de um trabalho ativo e potencializador.

Observou-se, ainda, que o Colégio Logosófico de Chapecó - SC aplica, na prática, as teorias desenvolvidas por Pecotche (2005), que partem do pressuposto de que a aprendizagem verdadeira é aquela que faz o sujeito sair da zona de conforto, tornando-se melhor a cada dia, por meio das oportunidades, desafios e superações diárias. Em suas obras, Carlos Bernardo González Pecotche $(2005,2019)$ considera que a maior liberdade 
do ser humano é a liberdade de pensar. Ele descrevia que o mundo precisa de pessoas livres que saibam pensar, ser autônomas e que esta liberdade só acontece por meio da investigação e do conhecimento.

Percebeu-se que os professores colaboram com a organização das informações, mas além disso, quando o estudante apresenta alguma dificuldade, os professores o conduzem a pensar favorecendo estratégias e motivação para a aprendizagem fecunda por meio dos conhecimentos cotidianos em conjunto com os científicos.

Assim, os professores relacionam situações de aprendizagem de acordo com o contexto real de vida do estudante, buscando construir o que Gadotti (1994) chama de aprendizagem significativa. Os estudantes se sentem responsáveis pelo seu processo de construção de conhecimentos, incluindo a auto iniciativa, que envolve os estudantes e os educadores.

A independência, a criatividade e a autoconfiança são facilitadas quando a autocrítica e a auto apreciação são básicas e a avaliação feita por outros tem importância secundária. A aprendizagem socialmente mais útil, no mundo moderno, é a do próprio processo de aprendizagem, uma contínua abertura à experiência e à incorporação, dentro de si mesmo, do processo de mudança (GADOTTI, 1994, p. 319).

Nota-se, de acordo com os referenciais já apresentados e as respostas dadas pelos professores, a realidade das características de "durabilidade e penetrabilidade da aprendizagem significativa" já que os estudantes recordam das vivências e saberes escolares construídos com essa metodologia no intuito de desenvolver os diversos aspectos de aprendizagem, levando-os sempre a pensar (GODOY, 2009).

Considerando que os saberes construídos nas relações entre sujeitos e os objetos não é apenas uma relação direta, mas mediada, buscaram-se respostas para a percepção docente acerca da qualidade das respostas de aprendizagem dos estudantes. Observou-se as seguintes respostas: 
QUADRO 4 - Qualidade das respostas de aprendizagem dos estudantes

\begin{tabular}{|l|l|}
\hline P1 & $\begin{array}{l}\text { [...] Talvez o que o aluno consegue exteriorizar [...] não seja tão amplo } \\
\text { quanto o que se passa na mente/cérebro de cada um deles. Passar por esse } \\
\text { processo de aprendizagem é muito importante, tanto para o agora como } \\
\text { para o futuro, pois a forma de pensar já é diferente desde "pequenos" e não } \\
\text { é porque são pequenos em tamanho que os conceitos e conteúdos são } \\
\text { pequenos. }\end{array}$ \\
\hline P2 & $\begin{array}{l}\text { As respostas de aprendizagem são muito boas [...] as crianças no geral } \\
\text { conseguem argumentar suas respostas, elaborar um raciocínio próprio sobre } \\
\text { o que aprendeu, compreendendo a lógica nos conhecimentos propostos. }\end{array}$ \\
\hline P5 & $\begin{array}{l}\text { Tenho me surpreendido com suas respostas. As respostas de muitos alunos são } \\
\text { resposta de uma criança de faixa etária maior. Suas produções são } \\
\text { coerentes, coesas, cheias de sentido e extensas pela idade em que estão. }\end{array}$ \\
\hline
\end{tabular}

Fonte: As autoras.

Percebeu-se nas respostas dadas que os professores refletem sobre a produção do saber, observando os avanços conceituais atitudinais e motores, realizando diversas abordagens de exercícios, materializando atividades eficazes e produtivas. Para os professores, a conquista da autonomia é um processo gradual que deve ser estimulado.

Os professores buscam a construção de conhecimentos científicos e não simplistas e, portanto, compreendem a importância de conhecer as situações cotidianas dos estudantes para, então, transformá-las em científicas. Os estudantes se aproximam das descobertas científicas para que, gradualmente, consigam diferenciar os saberes do senso comum e o conhecimento científico.

Segundo Vygotsky (2004) o conhecimento científico e o conhecimento espontâneo têm suas diferenças. Os cursos de desenvolvimento não se repetem, já que é algo que vai sendo transformado de acordo com o momento histórico. O estudante constrói conhecimento a partir da tomada de consciência e, então, consegue representar, por meio da linguagem, o conteúdo compreendido, não sendo um processo imediato, porque o sujeito é indeterminado.

O estudante, ao entrar no ensino fundamental, já realiza atividades voluntárias, portanto sabendo quais conteúdos deve dominar para sua 
compreensão. Os conhecimentos científicos e os espontâneos têm suas diferenças, sendo que os espontâneos não precisam de um pensamento abstrato, mas crítico porque agem direto com o objeto. O conhecimento científico, entretanto, apresenta estudos metodológicos que implicam no pensamento.

Para que o estudante compreenda o conteúdo, o professor precisa retomar o conceito constantemente, relembrando suas orientações e, são nestes momentos que o sujeito faz sua própria síntese mental, com os próprios elementos compreendidos, conseguindo discernir entre os conhecimentos científicos e os espontâneos, se autoavaliando e desencadeando modificações para a sociedade.

Na sequência, buscando oportunizar aos professores a reflexão sobre suas mudanças nas práticas pedagógicas, foi questionado se 'o trabalho com o projeto Kinesys influenciou sua prática pedagógica e, se sim, de que forma isto aconteceu'.

QUADRO 5 - Projeto Kinesys e mudanças nas práticas pedagógicas

\begin{tabular}{|l|l|}
\hline P1 & $\begin{array}{l}\text { [...] Evoluiu quanto a muitas práticas pedagógicas, como por exemplo na } \\
\text { forma de apresentarmos desafios na construção do conhecimento tendo o } \\
\text { registro como prática final na maioria das vezes[...]. }\end{array}$ \\
\hline P2 & $\begin{array}{l}\text { Sim! Pois nos anos escolares em que o Projeto ainda não está atuando, } \\
\text { consegui pensar em caminhos e atividades diferentes, que exercitem o } \\
\text { pensar dos alunos, antes de trazer respostas e conceitos prontos. }\end{array}$ \\
\hline P4 & $\begin{array}{l}\text { Influenciou. Não tanto na minha maneira de ver o meu componente } \\
\text { curricular, mas influenciou como vejo os demais componentes e todo o } \\
\text { processo de aprendizagem. }\end{array}$ \\
\hline P5 & $\begin{array}{l}\text { Tenho aprendido muito e me surpreendido com uma forma diferente de } \\
\text { ensinar, onde as crianças experimentam o conhecimento, veem acontecer. É } \\
\text { encantador! No início foi bem difícil, me senti incapaz de ensinar em muitos } \\
\text { momentos, mas fui em busca, procurei aceitar dentro de mim que realmente } \\
\text { muita coisa não sabia, mas que poderia e queria aprender. }\end{array}$ \\
\hline
\end{tabular}

Fonte: As autoras.

De acordo com as respostas obtidas, percebeu-se, por exemplo, a inovação do ensino no componente curricular da Matemática. Ao analisar 
as metodologias que eram utilizadas anteriormente, partia-se do pensamento empírico, então a formação do número era apresentado de forma direta aos estudantes. Agora, com o projeto Kinesys utiliza-se dos pressupostos de Davydov na aplicação da matemática com líquidos, ou calcular na reta numérica, ou aprender álgebra com 7 anos de idade, a inserção da escala cuisenaire, aprender multiplicação sem memorizar a tabuada, mas resolver os cálculos de forma consciente.

Pode-se constatar em uma das respostas, que o professor passou a ser visto com um olhar diferenciado diante de seu componente curricular. É comum nos depararmos com estudantes e professores que desenvolvem certa resistência por determinado componente curricular por não considerar uma certa usabilidade em seu contexto real e, isso, logicamente, reflete na aprendizagem.

Partiu-se do pressuposto que ninguém é detentor do conhecimento e que este é coletivo já que é a soma dos diversos conhecimentos individuais e, assim, percebeu-se que a construção do material é expressa de acordo com um currículo que permite a expressão de cultura acadêmica e científica, humanística e artística, assim todas as atividades independentemente do componente curricular são significativas promovendo aprendizagens relevantes para os estudantes.

De acordo com as respostas apresentadas anteriormente, percebeuse que os professores precisaram reinventar-se em suas práticas. No início encontraram insegurança por ser algo novo, mas no decorrer do tempo foram conhecendo o projeto, estudando, dedicando-se à compreensão de como ensinar os estudantes. Notou-se, ainda, que o papel principal da mudança dos professores foi transformar-se em um pesquisador do saber.

Na atualidade vive-se numa sociedade pautada na informação e no conhecimento, onde os sujeitos precisam estar sempre atualizados e conectados com o mundo globalizado. Assim a educação endereça a demanda de diferentes práticas pedagógicas para a constituição das pessoas, por meio da racionalidade, a qualidade de vida, sociabilidade, a sensibilidade, o desenvolvimento econômico e a sustentabilidade ambiental. 
Entende-se que não importa apenas a grande quantidade de informações apresentadas para os estudantes no processo de escolarização, mas é fundamental que eles compreendam qual é o sentido do conhecimento e como fazer o uso do mesmo em seu cotidiano, com autonomia e as possíveis soluções de problemas.

O projeto Kinesys trouxe inúmeras descobertas e modificações na maneira de pensar e atuar dos professores e, nesta direção, para finalizar a pesquisa buscou-se identificar 'experiências docentes no projeto Kinesys'.

QUADRO 6 - Experiências no projeto Kinesys

\begin{tabular}{|l|l|}
\hline P1 & $\begin{array}{l}\text { [...] vivo uma dicotomia, antes, não possuía material didático e tinha que criar } \\
\text { tudo, desde as atividades práticas até o registro de todo o processo pelo } \\
\text { aluno, o que deixava meu trabalho bastante cansativo e atribulado. Porém, eu } \\
\text { tinha liberdade de organizar e planejar dentro dos conteúdos previstos para } \\
\text { aquela turma. Agora com o projeto, tenho bastante material para trabalhar } \\
\text { com as crianças, mas sinto que perdi um pouco a liberdade de criação. }\end{array}$ \\
\hline P2 & $\begin{array}{l}\text { É difícil mudar o que já estava sólido para uma prática que ainda não tinha a } \\
\text { confiança da experiência. O tempo de estudo para capacitar-se ao que é } \\
\text { proposto foi um grande desafio tendo em vista que as demais demandas } \\
\text { continuaram acontecendo simultaneamente [...]. }\end{array}$ \\
\hline P3 & $\begin{array}{l}\text { No começo não foi fácil sair da forma tradicional, pois antes tinha organizado e } \\
\text { sabia tudo que precisava para minhas aulas. Hoje toda semana tenho que [.... } \\
\text { pensar no que posso colaborar com as outras disciplinas [...]. }\end{array}$ \\
\hline P5 & $\begin{array}{l}\text { [...] Lembro de algumas vezes, no início do ano em que o projeto iniciou, senti } \\
\text { vontade de voltar para os livros didáticos. [...] Hoje sinto uma gratidão enorme } \\
\text { pela escola que viu em mim uma capacidade que nem eu sabia que tinha. }\end{array}$ \\
\hline
\end{tabular}

Fonte: As autoras.

De acordo com as respostas apresentadas percebeu-se que as mudanças que o projeto Kinesys trouxe para as práticas docentes se configuraram em desafios, mas agregaram positivamente na sua carreira profissional.

\section{CONSIDERAÇÕES FINAIS}

Considerando o objetivo da pesquisa apresentada neste artigo, percebeu-se que a inserção do projeto Kinesys foi uma tarefa árdua e que, 
todos os envolvidos, de certa forma, transformaram suas práticas, mudaram seus materiais e, suas formas de pensar e agir sobre sua profissão.

Evidenciou-se que a inserção do projeto Kinesys proporcionou aos professores muitas oportunidades de formação por meio de desconstruções e construções de saberes. Também, são nítidos os impactos dos desafios impostos à docência já que, para participar do projeto, os professores precisaram passar por transformações na forma de conceber o processo de ensino-aprendizagem.

Como resultados, destaca-se que o coletivo docente participa do processo de planejamento das atividades, da elaboração de material didático específico, da validação do material didático e da prática de sala de aula visando à valorização de contextos reais de ensino-aprendizagem.

Destarte que, ao marcar a dimensão coletiva dos professores na responsabilidade pela construção do conhecimento intelectual, emocional e motor não se esgota esta pesquisa já que, de acordo com as os resultados obtidos por meio dos questionários, percebeu-se importantes manifestações da realidade dos professores envolvidos no projeto. Outros elementos do campo da didática podem ser ampliados e investigados em pesquisas futuras como, por exemplo, o processo de avaliação da aprendizagem, a formação continuada dos professores e os impactos de longo prazo na aprendizagem dos estudantes.

\section{REFERÊNCIAS}

BRASIL. Ministério da Educação - MEC, Secretaria de Educação Básica.

Orientações Curriculares para o Ensino Médio: Ciências da natureza, matemática e suas tecnologias. Brasília, 1999.

DAVYDOV, V. Problems of developmental teaching - The experience of theoretical and experimental psychological research. Soviet Education, Ago. 1988. Disponível em: https://www.tandfonline.com/doi/abs/10.2753/RPO10610405360411 . Acesso em: 20 jan. 2021.

FRIGOTTO, G. A interdisciplinaridade como necessidade e como problema nas ciências sociais. In: JANTSCH, A. P.; BIANCHETTI, L. (Orgs.).

Interdisciplinaridade: para além da filosofia do sujeito. Petrópolis: Vozes, 1995. 
FRISON, M. D. A perspectiva do especialista em educação: um olhar sobre Orientação Educacional - avanços e possibilidades. Santa Cruz do Sul. UNISC, set./dez., 2000.

GADOTTI, M. Aprendizagem e Desenvolvimento Infantil: Perspectivas Psicopedagógicas. Porto Alegre: Prodil, 1994.

GIL, A. C. Métodos e técnicas de pesquisa social. São Paulo: Atlas, 2008

GODOY, E. G. U. Contribuições da metodologia de projetos na implementação das tecnologias de informação e comunicação - TIC- nos processos educativos da Educação Básica. Dissertação (Mestrado em Educação Tecnológica) - Centro Federal de Educação Tecnológica de Minas Gerais, Belo Horizonte (MG), 2009.

LIBÂNEO, J. C. A didática e a aprendizagem do pensar e do aprender: a teoria histórico-cultural da atividade e a contribuição de Vasili Davydov. Rev. Bras. Educ., Rio de Janeiro, n. 27, Dec. 2004. Disponível em: http://www.scielo.br/scielo. Acesso em: 01 nov. 2020.

MINAYO, M. C. de S. (org.). Pesquisa Social. Teoria, método e criatividade. Petrópolis: Vozes, 2002.

MOURA, D. G.; BARBOSA, E. F. Trabalhando com projetos - planejamento e gestão de projetos educacionais. Petrópolis-RJ: Vozes, 2008.

NUNES, A.; CARVALHO, M. R. de. Questões metodológicas e epistemólogicas suscitadas pela Antropologia da Infância. ANPOCS, 2007.

PIRANDELLO, L. Seis personagens à procura de um autor. Peixoto Neto, São Paulo: 2004.

PECOTCHE, C. B. G. Logosofia: ciência e método. São Paulo: Logosófica, 2005.

PECOTCHE, C. B. G. Introdução ao conhecimento Logosófico. 4. ed. São Paulo: Logosófica, 2019.

SANTA CATARINA. Secretaria de Estado da Educação e do Desporto.

Proposta Curricular de Santa Catarina: Educação Infantil, Ensino Fundamental, Ensino Médio (formação docente para a educação infantil e séries iniciais). Florianópolis: COGEN, 1998.

KRAMER, S. et al. Encontros e desencontros de crianças e adultos na Educação Infantil: uma análise a partir de Martin Buber. Pro-Posições. 2016, vol.27, n.2. Disponível em: 
http://www.scielo.br/scielo.php?script=sci_arttext\&pid=S0103-

73072016000200135\&lng=en\&nrm=iso. Acesso em: 6 dez. 2020.

VASCONCELLOS, C. do S. Planejamento. Plano de Ensino-Aprendizagem e projeto educativo. São Paulo: Libertad, 1995.

VYGOTSKY, L. S. Psicologia Pedagógica. Tradução de Paulo Bezerra. 2.ed. São Paulo: Martins Fontes, 2004.

VYGOTSKY, L. S. A formação social da mente. - 6 ed. - São Paulo: Martins Fontes, 2003.

YIN, R. Estudo de caso: planejamento e métodos. Trad. Daniel Grassi - 2.ed. Porto Alegre: Bookman, 2001.

Recebido em: 03 de fevereiro de 2021. Aprovado em: 09 de junho de 2021 . Publicado em: 15 de julho de 2021. 